\title{
ANÁLISE DA QUALIDADE DA ÁGUA NO RIBEIRÃO MONTALVÃO, MUNICÍPIO DE ALFREDO MARCONDES/SP
}

\section{ANALYSIS OF WATER QUALITY IN RIBEIRÃO MONTALVÃO, CITY OF ALFREDO MARCONDES / SP}

\author{
Raul Selverio Fuso
}

Universidade Estadual Paulista - UNESP, Departamento de Planejamento, Urbanismo e Ambiente, Presidente Prudente, SP. Agência de fomento: Fundação de Amparo à Pesquisa do Estado de São Paulo (FAPESP)

E-mail: raulfuso@hotmail.com

RESUMO - O lançamento de efluente tratado em um corpo hídrico pode interferir na sua dinâmica, como, por exemplo, modificar as características físico-químicas da água. Logo, o presente trabalho propôs a realização de um monitoramento de variáveis limnológicas, em um trecho do Ribeirão Montalvão, a montante e jusante do lançamento de efluente tratado, e verificar quais estão de acordo ou não com a Resolução CONAMA nํ357/05. As variáveis oxigênio dissolvido (OD), potencial hidrogeniônico $(\mathrm{pH})$, condutividade elétrica (CE), temperatura (T) e turbidez (Turb) foram obtidas por meio de equipamentos digitais portáteis das marcas Instrutherm e Hanna. Estes resultados indicaram variações ao longo do perfil longitudinal das variáveis analisadas. Pôde-se verificar que, de acordo com os valores de referência da resolução para corpos d'água doce pertencentes a classe 2, somente o oxigênio dissolvido encontra-se fora dos padrões. Entretanto, foram observados valores elevados para outras variáveis, que podem ser referentes ao despejo de efluente.

Palavras-chave: Efluente Tratado; Ribeirão Montalvão; Monitoramento Limnológico; Oxigênio Dissolvido; Resolução CONAMA nำ357/05.

ABSTRACT - The release of treated effluent into a water body can interfere in its dynamics, for example, modify the physicochemical characteristics of the water. Therefore, this paper proposed the holding of a limnological variables monitoring in a section of Ribeirão Montalvão, upstream and downstream of the treated effluent release, and see which ones are agree or disagree with the CONAMA Resolution 357/05. The variables dissolved oxygen (DO), potential hydrogen $(\mathrm{pH})$, electrical conductivity $(E C)$, temperature $(T)$ and turbidity (Turb) were obtained by means of portable digital equipment brands Instrutherm and Hanna. These results showed variations along the longitudinal profile of the variables analyzed. It was verified that, according to the resolution of the reference values for bodies of fresh water belonging to Class 2 , only the dissolved oxygen is non-standard. 
However, higher values were observed for other variables that may be related to effluent disposal.

Keywords: Treaty Effluent; Ribeirão Montalvão; Limnological Monitoring; Dissolved Oxygen; CONAMA Resolution 357/05.

Recebido em: 28/06/2015

Revisado em: 05/08/2015

Aprovado em: 10/08/2015 


\section{INTRODUÇÃO}

Martins (1999) diz que a água é um elemento fundamental à vida. Seus múltiplos usos são indispensáveis a um largo espectro das atividades humanas, onde se destacam, entre outros, o abastecimento público e industrial, a irrigação agrícola, a produção de energia elétrica e as atividades de lazer e recreação.

Diante deste contexto, pode-se dizer que água é um tema transversal e intimamente relacionado ao bem-estar das populações. Segundo Farias (2006), o padrão de qualidade de vida de uma população está diretamente relacionado à disponibilidade e à qualidade da água, sendo esta, o recurso natural mais crítico e mais susceptível a impor limites ao desenvolvimento em muitas partes do mundo.

Esta água em questão, de acordo com Setti et al. (2000), é essencial à vida, sendo um bem de valor inestimável que deve ser protegido, uma vez que é um elemento necessário para quase todas as atividades humanas, além de também ser utilizada na geração de energia elétrica, em abastecimentos domésticos, entre outros.

Muitas vezes, este recurso não é visto como algo essencial, e sim como algo útil, sendo utilizado para despejos de resíduos ou efluentes, que interferem na dinâmica das águas.
O monitoramento limnológico é utilizado como uma ferramenta capaz de se analisar a influência destes despejos, sendo definido, segundo Freire (2010) como o processo de estudo, proporcionando uma visão temporal e espacial da qualidade da água, dando base para partir para a esfera da tomada de decisões.

Magalhães Júnior (2000) diz que o monitoramento da qualidade da água é um processo essencial à implantação dos instrumentos de gestão das águas, uma vez que permite a obtenção de informações estratégicas, acompanhamentos das medidas efetivas, atualização do banco de dados e atualização de decisões.

Este monitoramento, segundo Sanders et al. (1983) pode variar de acordo com o intuído da pesquisa, podendo ser utilizado para a detecção de violação dos padrões da qualidade da água, ou para a determinação de tendências temporais e espaciais em um corpo hídrico.

Tundisi e Tundisi (2008) cita algumas variáveis básicas a serem monitoradas, tais como temperatura, oxigênio dissolvido, condutividade elétrica e pH. Já Farias (2006) amplia esta lista, adicionando a ela sólidos dissolvidos, formas nitrogenadas, como nitrogênio amoniacal, nitrito e nitrato, fósforo total, entre outros.

Entre todas as variáveis citadas há uma que se sobressai, que é o oxigênio 
dissolvido, definido, segundo Farias (2006) como sendo indispensável à vida humana, aos animais e à maior parte dos microrganismos que vivem da água, sendo que, comparado ao ar, a água possui uma menor concentração deste gás, pelo fato de não ser muito solúvel.

Desta forma, o presente trabalho teve como objetivo a realização de monitoramento de variáveis limnológicas para se analisar a qualidade da água do Ribeirão Montalvão, classificado como classe 2 de acordo com o Decreto Estadual $\mathrm{n}^{\circ}$ 10.755 de 22 de novembro de 1977 (SÃO PAULO. Companhia Ambiental do Estado de São Paulo, 1977), utilizando, quando possível, a resolução CONAMA 357 de 17 de março de 2005 (BRASIL. Ministério do Meio Ambiente, 2005), no município de Alfredo Marcondes/SP.

\section{METODOLOGIA}

O monitoramento realizado para $\mathrm{o}$ desenvolvimento deste trabalho ocorreu no dia 20 de janeiro de 2015, em três seções do Ribeirão Montalvão e em uma seção localizada no tributário, no município de Alfredo Marcondes/SP.

As variáveis limnológicas amostradas em campo foram mensuradas por meio de aparelhos digitais portáteis das marcas Instrutherm e Hanna, como: oxigênio dissolvido (OD), $\mathrm{pH}$, condutividade elétrica
(CE), temperatura da água ( $\mathrm{T}$ ) e turbidez (Turb).

Os resultados obtidos em campo foram comparados, quando existentes, aos valores definidos pela resolução CONAMA ${ }^{\circ}$ 357 de 17 de março de 2005. Para as análises espaciais e temporais foram plotados gráficos utilizando-se o software Excel, versão 2013.

\section{RESULTADOS}

Os resultados referentes ao oxigênio dissolvido do Ribeirão Montalvão estão expressos na figura 1, sendo que as seções 1 , 2 e 4 referem-se ao canal principal e a seção 3 refere-se ao tributário.

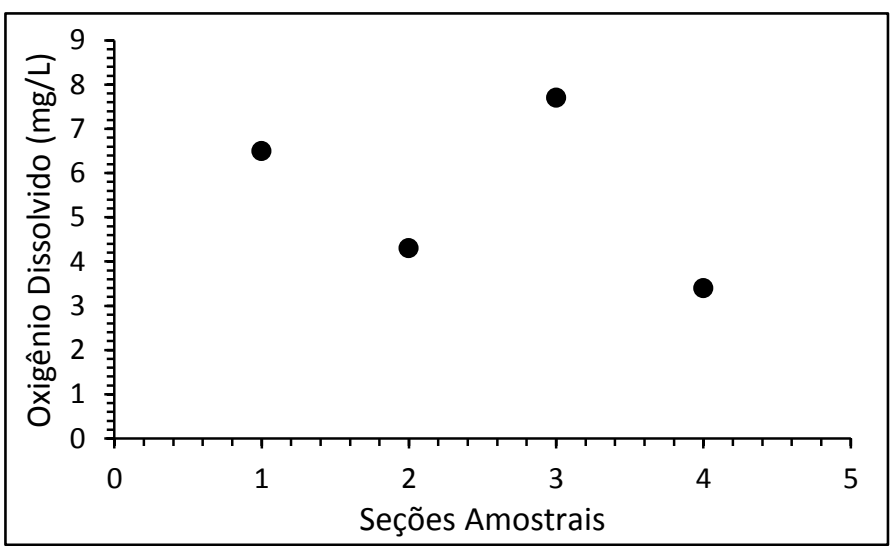

Figura 1: Valores de oxigênio dissolvido em diferentes seções amostrais.

Fonte: Acervo pessoal do autor, 2015.

Percebe-se que os valores para esta variável não se apresentaram constantes ao longo do perfil longitudinal do Ribeirão, principalmente em relação a seção 2 .

Os valores de condutividade elétrica em diferentes seções amostrais estão dispostos na figura 2. 


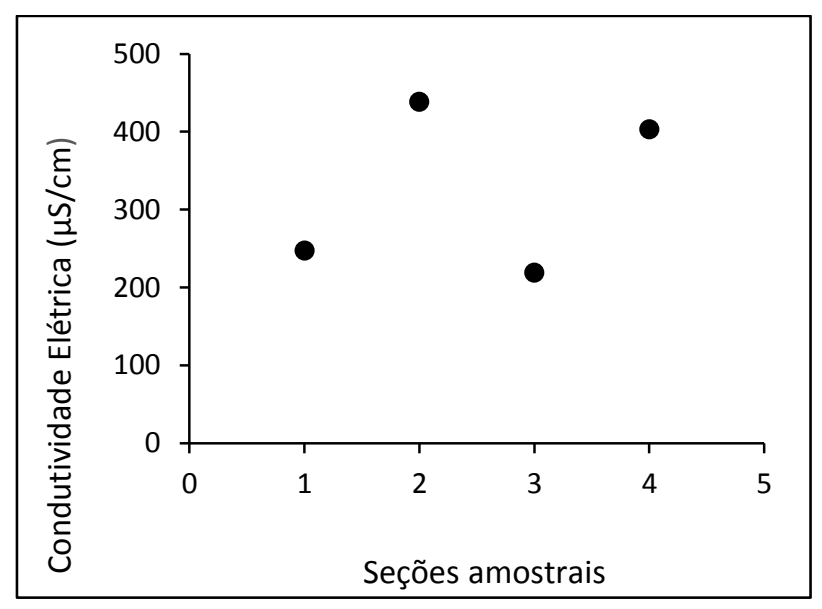

Figura 2: Valores de condutividade elétrica em diferentes seções amostrais.

Fonte: Acervo pessoal do autor, 2015.

A partir da análise da figura 2, nota-se um acréscimo na condutividade da seção 2 e um pequeno decrescimento na seção 4 .

Os valores de $\mathrm{pH}$ nos diferentes meses de amostragem e seções amostrais estão dispostos na figura 3.

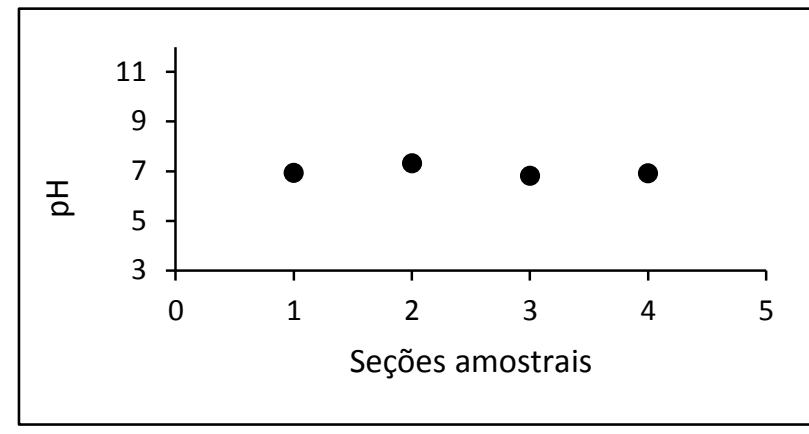

Figura 3: Valores de pH em diferentes seções amostrais.

Fonte: Acervo pessoal do autor, 2015.

Ao analisar a figura 3 é possível ver que o pH não apresenta variações ao longo do perfil longitudinal do Ribeirão, uma vez que o $\mathrm{pH}$ se mantém em uma faixa pequena, de 7.9 a 8.3 .
Os valores de temperatura em diferentes meses de amostragem e seções amostrais estão dispostos na figura 4.

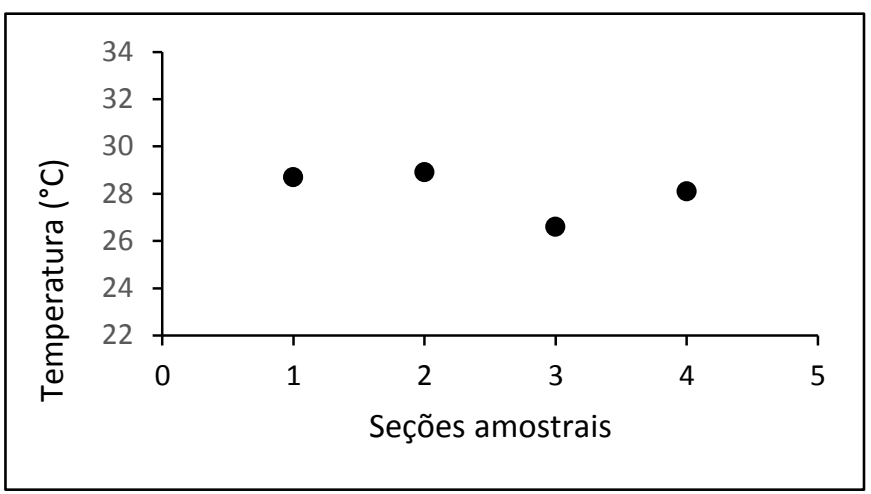

Figura 4: Valores de temperatura em diferentes seções amostrais

Fonte: Acervo pessoal do autor, 2015.

É possível observar que os valores de temperatura não sofreram drásticas variações durante o perfil longitudinal do corpo d'água.

Ainda, ao observar a figura 4 é possível notar que houve uma pequena variação relacionada ao canal principal e ao tributário.

Os valores de turbidez em diferentes meses de amostragem e seções amostrais estão dispostos na figura 5.

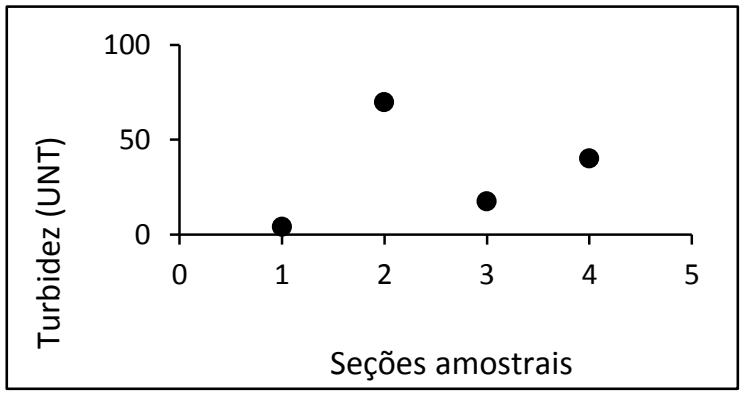

Figura 5: Valores de turbidez em diferentes seções amostrais

Fonte: Acervo pessoal do autor, 2015. 
A partir da análise da figura pode-se perceber que os valores de turbidez sofreram drásticas variações ao longo do perfil longitudinal, principalmente entre as seções 1 e 2.

\section{DISCUSSÃO}

O valore de oxigênio dissolvido decai drasticamente entre as seções 1 e 2 pois a montante da seção 2 há o lançamento de efluente tratado pela ETE do município de Alfredo Marcondes, o que contribui com uma carga orgânica que demanda oxigênio para ser estabilizada.

Segundo Von Sperling (2005), durante esta estabilização as bactérias fazem uso do oxigênio em seus processos respiratórios, causando sua redução. É vital para os seres aquáticos aeróbicos e é o principal parâmetro de caracterização de efeitos da poluição das águas por despejo humano.

Logo, este despejo de matéria orgânica e sua consequentemente estabilização fizeram com que o oxigênio dissolvido descaísse para valores abaixo de 5 $\mathrm{mg} / \mathrm{L}$ nas seções 2 e 4, valores estes em não conformidade, de acordo com a resolução CONAMA 357/05.

O acréscimo na condutividade referente a seção dois pode ser influenciado devido aos íons dissolvidos provenientes do despejo de efluente doméstico. 0 decréscimo referente a seção 4 pode ser relacionada a contribuição do tributário, que é representado pela seção 3 .

Os valores referentes ao $\mathrm{pH}$ se mantêm em conformidade com a resolução CONAMA 357/05, uma vez que a mesma define um limite de 6,0 a 9,0.

Em relação a temperatura, seus valores mais elevados podem ser associados ao período em que o monitoramento foi realizado, sendo período de verão, que apresenta uma maior radiação solar, favorecendo o aumento de temperatura.

Vale salientar que, de acordo com dados da estação meteorológica da UNESP de Presidente Prudente, a temperatura média no dia foi de $29,2^{\circ} \mathrm{C}$, o que evidencia a alta temperatura do Ribeirão Montalvão.

Branco (2011) diz que a turbidez de uma amostra de água é o grau de atenuação de intensidade que um feixe de luz sofre ao atravessá-la, devido à presença de sólidos em suspensão, tais como partículas inorgânicas, como areia, silte e argila, e de detritos orgânicos, algas e bactérias, plâncton em geral, etc.

A grande variação dos valores de turbidez entre as seções 1 e 2 podem estar associadas ao despejo de efluente que contribui com o aumento destes sólidos em suspensão, que deixa a água mais turva e impede a entrada de luz.

A resolução CONAMA 357/05 define que os valores máximos de turbidez para 
córregos classe 2 são de 100 UNT. Deste modo, os valores de turbidez do Ribeirão Montalvão se encontram em conformidade com a resolução.

\section{CONCLUSÃO}

Por meio das análises dos resultados obtidos em campo foram observadas variações ao longo do perfil longitudinal do Ribeirão em quase todas as variáveis e seções amostrais, tendo somente o $\mathrm{pH}$ como sendo uma variável mais constante.

Algumas variáveis expressaram mais variação do que outras, tais como oxigênio dissolvido e condutividade elétrica, sendo que estas variações ocorreram de forma mais acentuada após o despejo de efluente tratado da ETE de Alfredo Marcondes no canal principal.

Analisando-se 0 enquadramento destas variáveis em relação a resolução CONAMA n $357 / 05$ pôde-se perceber que, dentre as variáveis que são listadas pela resolução, somente o oxigênio dissolvido apresentou valores abaixo do mínimo necessário.

Isto mostra que os usos preponderantes para o Ribeirão Montalvão no trecho analisado estão prejudicados, como: i) à proteção das comunidades aquáticas; ii) à recreação de contato primário, tais como natação, esqui aquático e mergulho; iii) à irrigação de hortaliças, plantas frutíferas e de parques, jardins, campos de esporte e lazer, com os quais o público possa vir a ter contato direto; e iv) à aquicultura e à atividade de pesca.

As outras variáveis, tais como temperatura e condutividade elétrica, não são enquadradas na resolução, mas, segundo a Cetesb, córregos com condutividade elétrica acima de $100 \mu \mathrm{S} / \mathrm{cm}$ apresentam sinais de degradação, logo, percebe-se que há um desequilíbrio em relação a esta variável.

\section{AGRADECIMENTOS}

A Fundação de Amparo à Pesquisa do Estado de São Paulo (FAPESP) pelo apoio financeiro ( $n$ - 2014/06702-0).

\section{REFERÊNCIAS}

BRASIL. Ministério do Meio Ambiente. Conselho Nacional do Meio Ambiente. Resolução CONAMA N 357, de 17 de março de 2005. Disponível em: <http://www.mma.gov.br/port/conama/res/ res05/res35705.pdf>. Acesso em: 04 abr. 2015.

FARIAS, M.S.S. Monitoramento da qualidade da água na bacia hidrográfica do Rio Cabelo. 2006. 152 p. Tese (Doutorado em Engenharia Agrícola) - Centro de Tecnologia e Recursos Naturais, Universidade Federal de Campina Grande, Campina Grande.

FREIRE, R. Monitoramento da qualidade da água da bacia hidrográfica do Ribeirão Maringá. 2010. 175 p. Dissertação (Mestrado em Engenharia Química) - Universidade Estadual de Maringá, Maringá. 
MAGALHÃES JUNIOR, A.P. A situação do monitoramento da águas no Brasil. Revista Brasileira de Recursos Hídricos, Belo Horizonte, v. 5, n. 3, p. 113-135, set. 2000.

MARTINS, G. Reuso e reciclo de águas em indústrias químicas de processamento dióxido de titânio. 1999. 69 p. Monografia (Especialização) - Escola Politécnica, Universidade Federal da Bahia, Salvador.

SANDERS, T.G. et al. Design of network for monitoring water quality. Highlands Ranch: Water Resources Publications, 1983.

São Paulo. Companhia Ambiental do Estado de São Paulo. Decreto $\mathbf{N}^{\circ} \mathbf{1 0 . 7 5 5}$, de 22 de novembro de 1977 . Disponível em: <http://www.cetesb.sp.gov.br/licenciamento o/legislacao/estadual/decretos/1997_Dec_Es t_10755.pdf>. Acesso em: 24 jun. 2015.

SETTI, A.A. et al. Introdução ao gerenciamento de recursos hídricos. 2 ed. Brasília: Agencia Nacional de Energia Elétrica, Superintendência de Estudos de Informações Hidrológicas, 2000.

TUNDISI, J.G; TUNDISI, T.M. Limnologia. São Paulo: Oficina de Textos, 2008.

VON SPERLING, M. Introdução à qualidade das águas e ao tratamento de esgotos. 3. ed. Belo Horizonte: DESA-UFMG, 2005. 